\title{
THERMAL DECOMPOSITION OF ENERGETIC MATERIALS BY REAXFF REACTIVE MOLECULAR DYNAMICS
}

\author{
Luzheng Zhang, Sergey V. Zybin, Adri C.T. van Duin, \\ Siddharth Dasgupta, and William A. Goddard III *
}

\author{
Materials and Process Simulation Center, Beckman Institute (139-74) \\ California Institute of Technology, Pasadena, California 91125
}

\begin{abstract}
We report the study of thermal decomposition of 1,3,5-trinitrohexahydro-s-triazine (RDX) bonded with polyurethane (Estane) and of the bulk hydrazine by molecular dynamics (MD) simulations equipped with the reactive force field (ReaxFF). For the polymer binder explosive, the simulation results show that the thermal decomposition of RDX is affected by the presence of the polymer binder Estane. Generally, with addition of Estane the decomposition of RDX slows down. Final products including $\mathrm{N}_{2}, \mathrm{H}_{2} \mathrm{O}, \mathrm{CO}, \mathrm{CO}_{2}$ and intermediates $\mathrm{NO}_{2}, \mathrm{NO}$ and $\mathrm{HONO}$ have been identified from the thermal decomposition processes. For the bulk hydrazine, it is found that with the increase of temperature, its decomposition increases and more $\mathrm{N}_{2}$ and $\mathrm{H}_{2}$ are generated, but $\mathrm{NH}_{3}$ molecules are consumed much faster at higher temperatures. This simulation work provides us an approach to quickly test the response of various energetic materials to thermal conditions.
\end{abstract}

Keywords: molecular dynamics, reactive force field, thermal decomposition, energetic materials, RDX, plastic bonded explosives, and hydrazine.

PACS: $02.70 . \mathrm{Ns}$, 82.30Lp, 82.20.Wt, 82.33.Vx

\section{INTRODUCTION}

A detail description of the chemical reaction mechanisms of condensed energetic materials at high densities and temperatures is essential for understanding events that occur at the reactive front of these materials under combustion or detonation conditions. Plastic-bonded explosives (PBX) are the most common munitions. The main purpose of binding high explosives to polymers is to reduce their sensitivity to shock, friction and impact. One way to assess sensitivity is to study the thermal decomposition behavior of the material, as temperature is one of the main causes of initiation for explosives ${ }^{[1]}$. The thermal decomposition of PBXs has been studied by various research groups using experimental techniques such as thermogravimetry (TG) ${ }^{[2,3]}$, differential scanning calorimetry (DSC) ${ }^{[2]}$, differential thermal analyzer (DTA) ${ }^{[2,3]}$, and triple quadrupole mass spectrometer (TQMS) ${ }^{[4]}$. However, the detailed information about the reaction chemistry related to thermal decomposition of PBXs was not obtained from those experimental studies. Such information is important for us to understand the whole procedure of the thermal decomposition of an explosive, particularly with addition of a polymer binder.

In order to obtain atomic-scale information on the influence of polymer binders on the sensitivity of high explosives, we employed the reactive force field (ReaxFF) to a series of cook-off processes. We have demonstrated the transferability of the method by developing potentials for hydrocarbons ${ }^{[5]}$, nitramines ${ }^{[6,7]}$, silicon/silicon oxides ${ }^{[8]}$, aluminium/aluminium oxides ${ }^{[9]}$, and transition metal chemistry ${ }^{[10]}$. In this work, we used the ReaxFF to study thermal decomposition of RDX $\left(\mathrm{C}_{3} \mathrm{H}_{6} \mathrm{~N}_{6} \mathrm{O}_{6}\right)$ in the presence and absence of Estane chains and to determine how its sensitivity changes with the addition of the Estane. In addition, similar cook-off processes were simulated on the bulk hydrazine $\left(\mathrm{N}_{2} \mathrm{H}_{4}\right)$, which is an important ingredient in rocket propellants. These simulations show us the feasibility of the ReaxFF to various energetic materials under thermal conditions. 


\section{SIMULATION DETAIL}

We studied the system containing RDX with the Estane (Figure 1). To set up the packing structure of $\mathrm{RDX} /$ Estane we took an RDX-crystal and extended its periodic cell along the X-direction [001], thus created a void in which Estane chains were inserted. The overall density of Estane chains is $1.18 \mathrm{~g} / \mathrm{cm}^{3}$. The density of RDX molecules in both pure RDX and RDX-Estane is very similar $\left(\sim 1.80 \mathrm{~g} / \mathrm{cm}^{3}\right)$. The resulted RDX-Estane packing structure is illustrated in Figure 2. The system contains 64 RDX molecules and 2 Estane chains.
The initial packing structure of RDX and Estane was minimized with the ReaxFF and equilibrated at $100 \mathrm{~K}$ for $10 \mathrm{ps}$, followed by a NPT-MD for $4 \mathrm{ps}$ to remove possible stress inside the structure. The final structure was then used to run 16-ps NVTMD simulation for the cook-off process, in which the system was heated from $100 \mathrm{~K}$ to $2100 \mathrm{~K}$ with a rate of $250 \mathrm{~K} / \mathrm{ps}$ in the first $8 \mathrm{ps}$ and then kept at $2100 \mathrm{~K}$ for another 8ps. A Berendsen-thermostat with a temperature constant of $50 \mathrm{fs}$ was used to control the temperature in all simulations. MD time step was set to $0.20 \mathrm{fs}$.

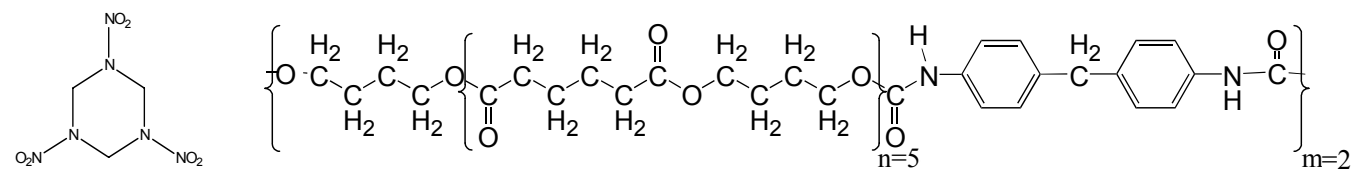

FIGURE 1. Molecular structures of RDX (left) and Estane chain (right).

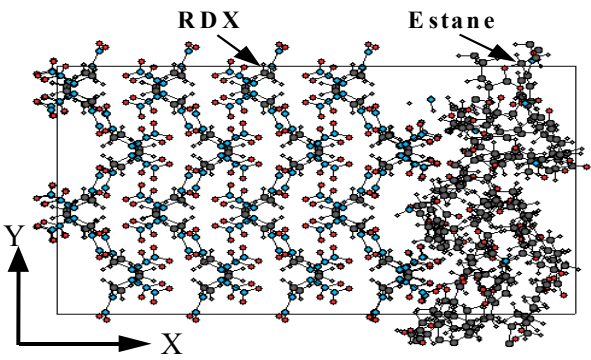

FIGURE 2. The equilibrated packing structure of RDX with Estane chains.

\section{RESULTS AND DISCUSSION}

Figure 3 gives the total fragments produced during the cook-off simulations for pure RDX and for RDX-Estane. It is observed that the change in total fragments is very different. For the pure RDX, it starts to increase slowly at around $2 \mathrm{ps}$, while it only begins to increase after $4 \mathrm{ps}$ for the RDXEstane. With the increase of temperature (from $1100 \mathrm{~K}$ at $4 \mathrm{ps}$ to $2100 \mathrm{~K}$ at $8 \mathrm{ps}), \mathrm{RDX}$ molecules decompose continuously and much more new fragments are formed during the cook-off process. The total number of fragments for pure RDX is always larger than that for the RDX-Estane, indicating that the polymer binder Estane reduces the thermal decomposition process of pure RDX. For a comparison, Figure 3 also plots total fragments for the system with Estane chains only under the same cook-off condition. It shows that the polymer chains do not decompose at all during the whole cook-off process, because the temperature and heating rate is not high enough to break the chemical bonds within the Estane chains. In order to confirm that the ReaxFF can be used for simulations with Estane chains, we tested another case in which the Estane chains were heated to $2100 \mathrm{~K}$ at a slower rate of $80 \mathrm{~K} / \mathrm{ps}$ and kept at $2100 \mathrm{~K}$ for about $25 \mathrm{ps}$. It was found that the polymer chains began to decompose and major products were identified from the simulation, which qualitatively agrees with those from experimental measurements ${ }^{[11]}$. This test run shows that initial decomposition temperature decreases when the hearing rate decreases. We have extensively studied the effect of heating rate on the decomposition of other energetic materials such as hydrazine ${ }^{[13]}$, but only one heating rate $(250 \mathrm{~K} / \mathrm{ps})$ was used for RDX and RDX-Estane in this study. We also calculated the pressure during the cook-off simulations. The pressure for pure RDX $(9.9 \mathrm{GPa})$ is higher than that for RDX-Estane (7.8GPa), because more fragments are generated in the cook-off processes for pure RDX than that for RDX-Estane.

When RDX molecules decompose, the total potential energy in the system generally decreases. We have observed the difference in potential energy, as shown in Figure 4. The potential energy 
decreases more quickly in the constant temperature region ( $\mathrm{t}>8 \mathrm{ps}$ ) for pure $\mathrm{RDX}$ than that for RDXEstane. It suggests that more RDX molecules decompose in pure RDX than those in RDXEstane. For pure Estane chains (lower panel in Fig.4), however, the potential energy change in the constant region (after 8ps) becomes stable, indicating that no Estane chains decompose.

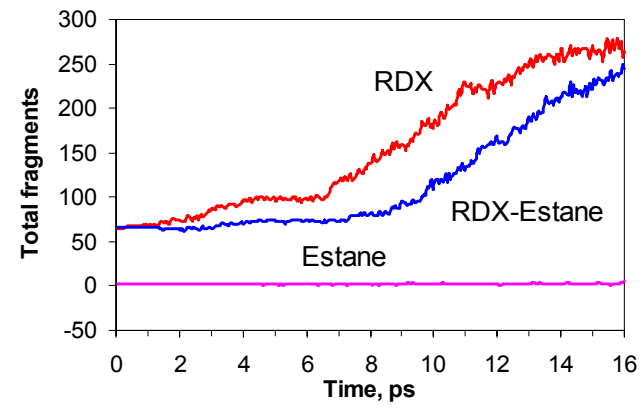

FIGURE 3. Total fragments from cook-off study of the systems pure RDX, RDX-Estane and pure Estane.

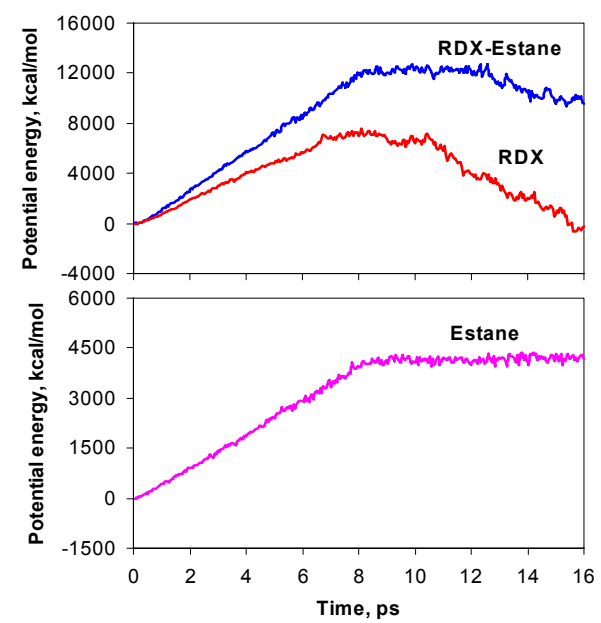

FIGURE 4. Potential energy for the systems of RDX, RDX-Estane and Estane chains. For a comparison, relative values of the potential energy are shown here.

In order to understand how the Estane chains affect RDX thermal decomposition, we analyzed the compound distribution during the cook-off simulations with $50 \mathrm{fs}$ intervals, i.e., we recorded the trajectory of each system every $50 \mathrm{fs}$ and then analyzed molecular fragments for each frames. Figure 5 gives species analyses for the systems RDX and RDX-Estane. For pure RDX, the RDX molecules dissociate very slowly at early times, forming many $\mathrm{NO}_{2}$ molecules. With the increase of temperature, more RDX molecules decompose and new species such as $\mathrm{HONO}, \mathrm{N}_{2}, \mathrm{H}_{2} \mathrm{O}, \mathrm{CO}$ and $\mathrm{CO}_{2}$ are formed. When temperature reaches $2100 \mathrm{~K}$ (at 8ps), about 19 RDX molecules are left in the system, while 40 RDX molecules are left for RDXEstane. These results show that when the Estane chains are bonded to the RDX crystal, the decomposition of RDX slows down, indicating that the reactivity/sensitivity of $\mathrm{RDX}$ to thermal conditions is reduced. This finding from these cook-off simulations agrees with that from experimental observations ${ }^{[12]}$. For example, the number of $\mathrm{N}_{2}$ molecules formed by the thermal condition in pure RDX is much more than that in RDX-Estane. As we know, the formation of $\mathrm{N}_{2}$ molecules releases energy to the system, resulting in a quick decomposition of RDX molecules. More secondary reactions occur in the system and a further formation of products (e.g., $\mathrm{H}_{2} \mathrm{O}, \mathrm{CO}$, and $\mathrm{CO}_{2}$ ) is found.
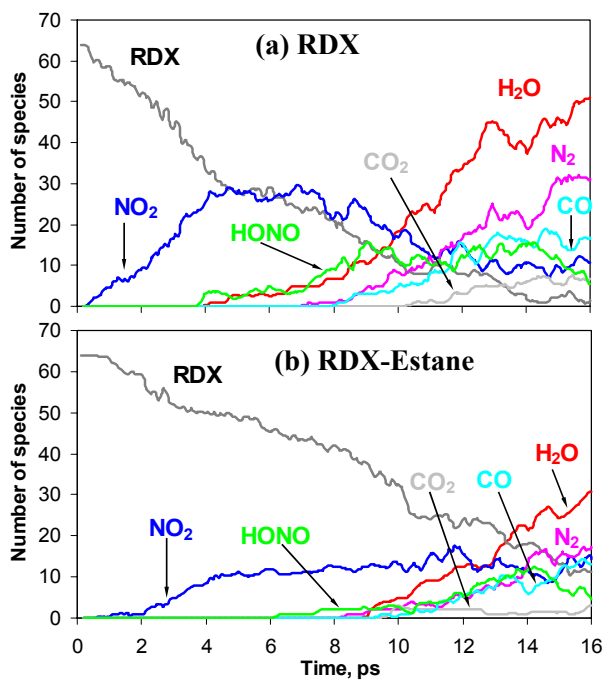

FIGURE 5. Species analyses for the systems of (a) RDX and (b) RDX-Estane. The decomposition of RDX slows down with the addition of polymer binder Estane.

To apply the ReaxFF to other systems, we also performed similar cook-off simulations of the bulk hydrazine $\left(\mathrm{N}_{2} \mathrm{H}_{4}\right)$ under different thermal conditions. In these simulations, the systems with pure hydrazine (bulk density is $0.554 \mathrm{~g} / \mathrm{cm}^{3}$ ) were heated from $1000 \mathrm{~K}$ to specified temperatures $(2000 \mathrm{~K}, 3000 \mathrm{~K}$ and $4000 \mathrm{~K})$ at $100 \mathrm{~K} / \mathrm{ps}$ and kept at constants for 20-40ps (Figure 6a). These 
simulations give us the brief information on chemical events that occur in hydrazine under such thermal conditions. The detail species analyses are shown Figure 6b. Generally, with the increase of temperature the decomposition of hydrazine increases. More products $\mathrm{N}_{2}$ and $\mathrm{H}_{2}$ are generated and some intermediates such as $\mathrm{N}_{2} \mathrm{H}_{3}, \mathrm{~N}_{2} \mathrm{H}_{2}$ and $\mathrm{NH}_{2}$ are identified. For the product $\mathrm{NH}_{3}$, its formation time is very similar ( $\sim 9 \mathrm{ps})$ in all three cases, but more $\mathrm{NH}_{3}$ molecules are consumed at higher temperatures because more secondary reactions occur at such temperatures. We have studied the effect of other factors such as heating rate and pressure and found that temperature and heating rate have more effect than pressure does [13].

(a)

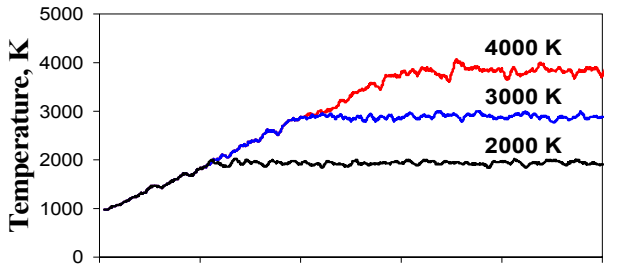

(b)
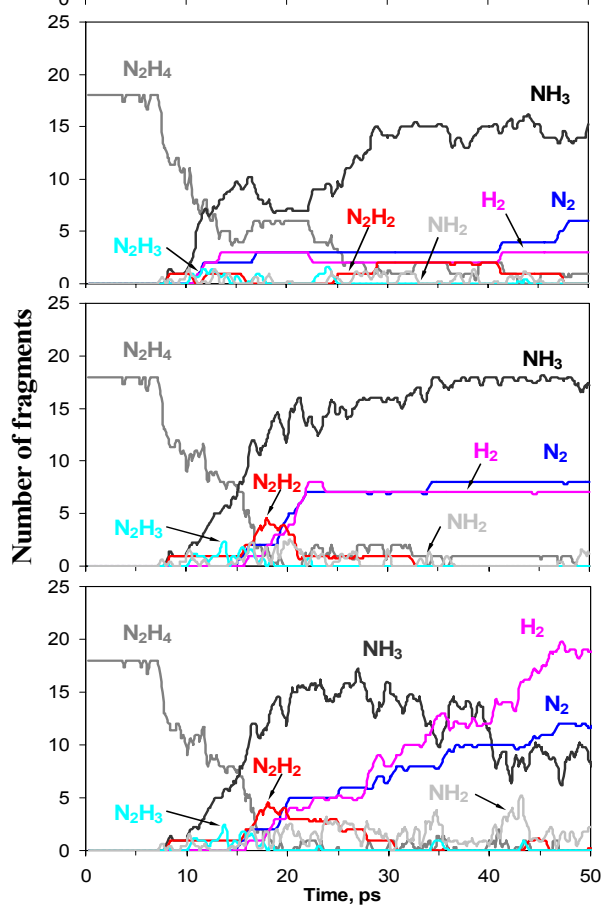

FIGURE 6. (a) Temperature profiles and (b) species analyses for hydrazine under different thermal conditions.
In summary, we performed ReaxFF-MD simulations for RDX, RDX-Estane and hydrazine under different thermal conditions. Thermal decomposition of pure RDX crystal is influenced by the presences of the polymer binder. The products from hydrazine decompositions depend on various factors such as heating rate, temperature and pressure. The simulation results suggest that the ReaxFF can provide a computationally inexpensive tool to evaluate the stability/sensitivity of various energetic materials under thermal conditions.

\section{ACKNOWLEDGEMENTS}

Funding for this work was provided by ONR and ARO-MURI.

\section{REFERENCES}

1. Cooper P.W., Explosive Engineering, Wiley-VCH, New York, 1996.

2. Singh G., Felix S. P. and Soni P., Thermochimica Acta 399, 153 (2003).

3. Ger M. D., Hwu W. H. and Huang C. C., Thermochimica Acta 224, 127 (2003).

4. Lee Y., Tang C.-J. and Litzinger T. A., Combustion and Flame 117, 795 (1999).

5. Strachan A., van Duin A.C.T., Chakraborty D., Dasgupta S. and Goddard III W.A., Phys. Rev. Letters 91, 09301 (2003).

6. Strachan A., Kober E., van Duin A.C.T., Oxgaard J. and Goddard III W.A., J. Chem. Phys. 122, 054502 (2005)

7. van Duin A.C.T., Dasgupta S., Lorant F. and Goddard III W.A., J. Phys. Chem. A 105, 9396 (2001).

8. van Duin A.C.T., Strachan A., Stewman S., Zhang Q., Xu X. and Goddard III W. A., J.Phys.Chem. A 107, 3803 (2003).

9. Zhang Q., Cagin T., van Duin A.C.T., Goddard III W.A., Qi Y. and Hector L., Phys.Rev.B 69, 045423 (2004).

10. Nielson K., van Duin A.C.T., Oxgaard J., Deng W and Goddard III W.A., J.Phys.Chem. A. 109, 493 (2005).

11. Font R., Fullana A., Caballero J. A., Candela J. and Garcia A., J. Analytical and Applied Pyrolysis 5859, 63 (2001).

12. Taver C. M. and Tran T. D., Combustion and Flame 137, 50 (2004).

13. Zhang L., van Duin A.C.T., Zybin, S. V. and Goddard III W.A., submitted to J. Chem. Phys. (2006). 